\title{
Improving the investment environment in the region by tools of competency-based HR management
}

\author{
Alexandr Kokovikhin \\ Management and IT Institute, Ural State University of Economics, Yekaterinburg, Russian Federation; \\ gov66@inbox.ru
}

Keywords: Investment environment, HR management.

\begin{abstract}
The aim of this paper - to present tools of competency-based HR management, using in regional HR policy for improving the investment environment. Theoretical basis of regional HR policy, presented in this paper are institutional theory (institutional barriers and institutional filters conception) and resource theory (core competences conception). The model of competence formation and implementation was given. There are institutional barriers and institutional filters - managerial factors in the governance mechanism, according proposed methodological approach. Proposals at management tools have been developed, that strictly conform to managerial factors, such as institutional barriers and institutional filters. Methodology research includes publication research, an in-depth analysis of semi-structures interviews with top managers, and observation of aspects that cover practices used in human resource management. A study of management practices in 110 organizations of the Sverdlovsk oblast showed that managers used tools of Dual Education Model, National Qualification Framework and employers labour mobility programs in education and hr-practice. According competency-based management concepts, the mechanisms of National Qualifications Frameworks: certification of professional qualifications and professional public expertise of educational programs needs to be used in Regional Human Resource Policies for Industrial Growth. Results of this research are useful for elaborating personnel recruiting systems, systems of competence and qualification, competency-based management and regional human resource policies.
\end{abstract}

\section{Introduction}

The national rating of investment environment in regions of Russian Federation assesses the availability of labour resources having necessary qualifications, the results are obtained through the survey of legal entities and individual entrepreneurs who recruited new employees in the last 12 months. The national rating of investment environment analyzes 4 kinds of activity: industry, agriculture, construction, transport and communications.

The respondents are to use the following criteria for satisfaction assessment:

1) the availability of sufficient labour resources with necessary qualifications in the subject of the Russian Federation;

2) the amount of time spent on the search for labor resources with the necessary qualifications;

3) monetary cost of search labor resources;

4) found the professionalism of the workforce.

Depending on the level of satisfaction of investors put: 1 point - very bad; 2 - bad; 3 points - good; 4 points - good; 5 points - excellent. The average values for 5 groups of regions (A - regions with the best results, $\mathrm{E}$ - regions with the worst results) slightly range from "medium" to "good". In the country as a whole, the values indicating the level of investor satisfaction with the availability of labour resources possessing the required qualifications is lower than the indicators in other areas of assessment (Fig. 1). In the National rating of the investment climate in 2016, prepared by the end of 
2015, the Sverdlovsk Region is included in the second group of five. Compared to the previous year there is an increase of 12 positions ${ }^{1}$.

At the same time, "entrepreneur satisfaction with the availability of labor of the required qualification" made 3.1 points, which corresponds to group $\mathrm{E}$ of the regions with the lowest indicator values. It should be noted that the rating position and the results dynamics are considered in evaluating the efficiency of heads of Executive authorities in the subjects of the Federation, which makes rating an effective mechanism of motivation for the Executive authorities in the subjects of the Federation. It motivates them to achieve the objectives of the state policy of human resources management at the regional level. In order to increase investment attractiveness of the region, on December 302014 , the Prime Minister of the Sverdlovsk region approved a Plan of measures (roadmap) on improving the position of the Sverdlovsk region in the National rating of investment climate in the regions in 2015-20172. The road map sets target indicators of "entrepreneur satisfaction with the availability of labour of the required qualification" for $2015,2016,2017$, being $3.2 ; 3.5 ; 4$. 0 points respectively. The indicator value achieving 4.0 points will allow the Sverdlovsk region to enter the "top-5" regions in terms of entrepreneur satisfaction with the availability of labor of the required qualifications.

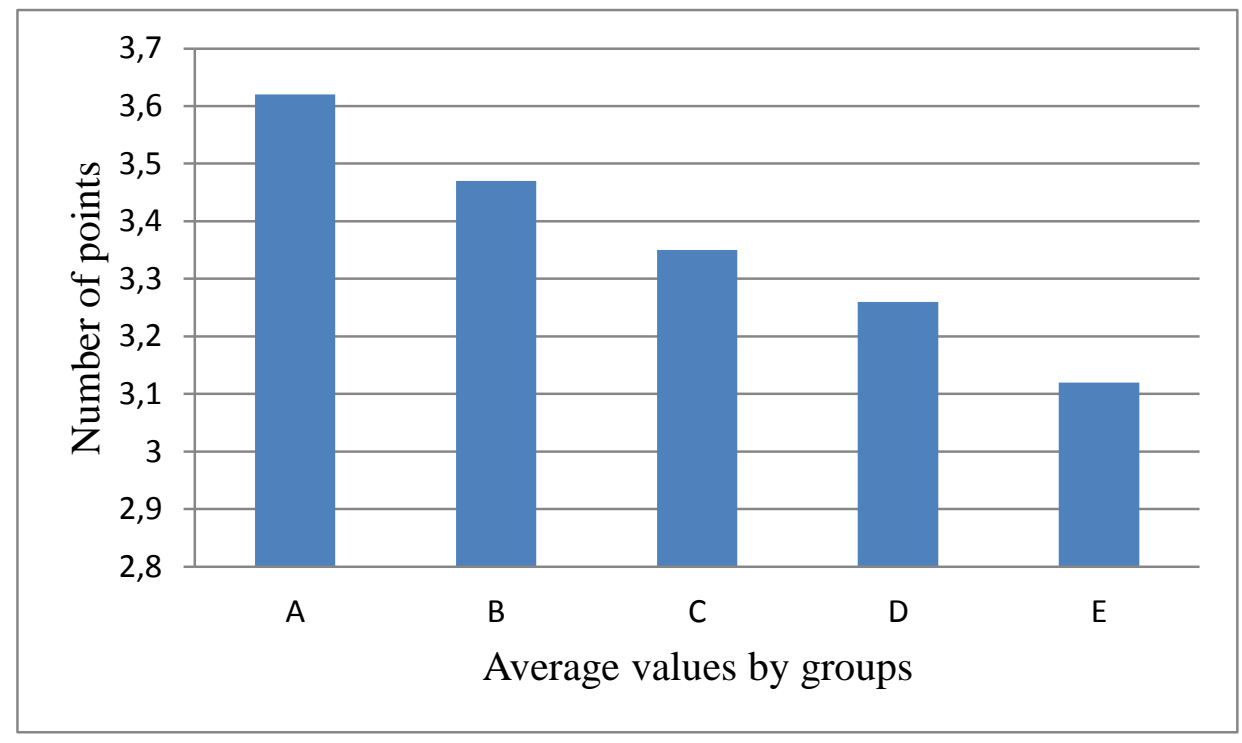

Fig. 1. The results of the National rating of the investment climate on the indicator "Assessment of the availability of labor of the required qualification" in 2015 (Compiled based on the rating of the investment climate in the subjects of the Russian Federation).

A significant part of the Roadmap activities are to be implemented by local authorities. The motivation of the municipal authorities to increase the investment attractiveness of the territory is provided by the introduction of the rating mechanism. One of the parameters evaluated through the survey of entrepreneurs is «satisfaction with the availability of labor of the required qualification".

Unlike the regional management level, for which a number of human resources management recommendations were developed to increase the investment attractiveness of the region, there are far from plenty of those at the municipal level. The article attempts to contribute to filling this gap. At the same time, the information on the entrepreneur assessment of the availability of qualified labour in the Sverdlovsk region, obtained while implementing the state contract for the Ministry of Investments and Development of the Sverdlovsk Region in 2015, helped to conduct another research.

\footnotetext{
${ }^{1}$ National rating of the investment climate in the constituent entities of the Russian Federation. Access mode: http://www.investinregions.ru/rating.

${ }^{2}$ The Plan of measures (roadmap) on improving the position of the Sverdlovsk region in the National rating of investment climate in the regions in 2015-2017. Access mode: http://mir.midural.ru/sites/default/files/files/ dorozhnaya_karta_-_utverzhdenie.pdf
} 
Competency-based management includes an approach to the description, assessment and development of the person within which the behavior of the person is considered to be the manifestation of his competences [1]. In scientific literature there are three main directions of competence-based approach: American (behavioural), English (functional) and integrated in France, Germany and Austria [2]. The common things in these directions help to define "competences" as behavioural characteristics which the individual must have or which he must acquire to effectively cope with the work [3].

The model of competence formation and implementation, developed by prof. Robert Nizhegorodtsev, presented at fig. 2 [4]. There are institutional barriers and institutional filters managerial factors in the governance mechanism, according methodological approach, proposed by author. The aim of the researching is to find management tools of competency-based HR management, using in regional HR policy, that strictly conform to managerial factors, such as institutional barriers and institutional filters.

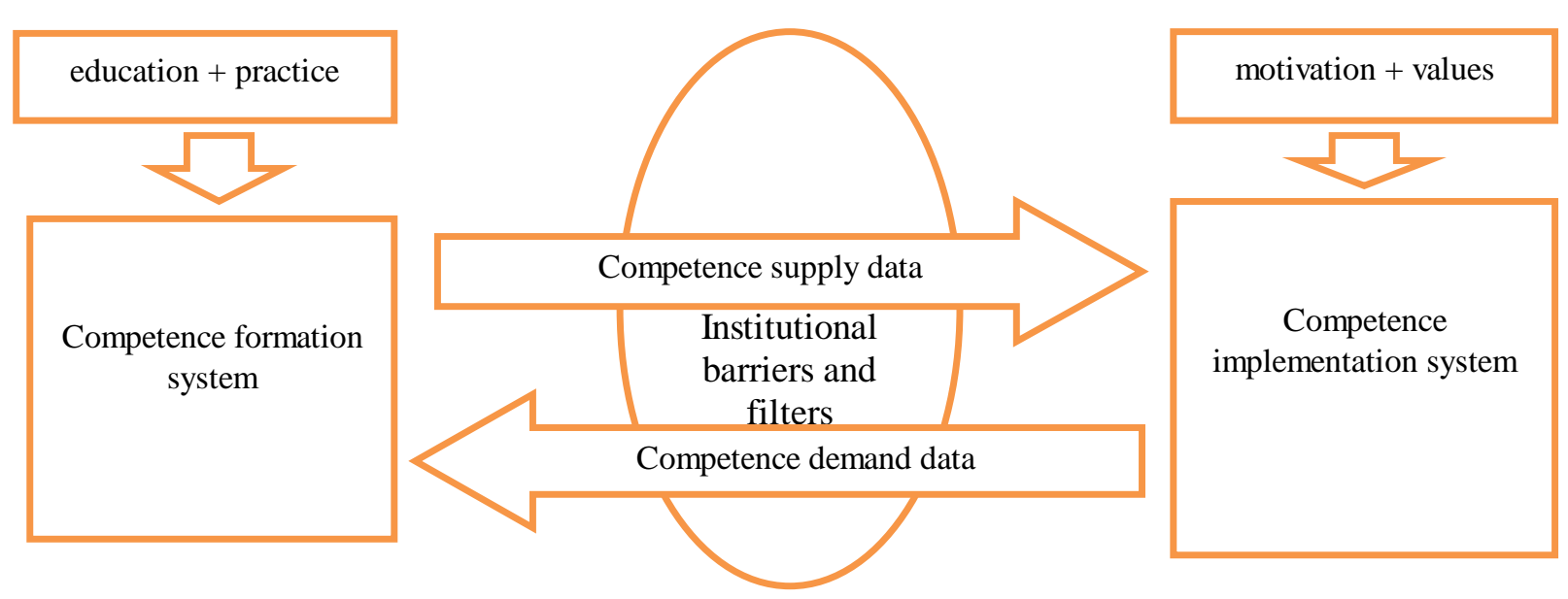

Fig. 2. Model of Competence formation and implementation system, developed by prof. R. Nizhegorodtsev [4].

\section{Methods.}

The research methodology included accumulation of data and information using different methods: analyzing scientific publications, conducting structured interviews and econometric analysis. Data presented both historical and current information in the given social sphere. The reasons for using the specified methods are connected with the research of social phenomena: national culture, values, behavior and personnel management practices. Thus, the collection, selection and analysis based on methods of interpretation (they reveal ideas (meanings) emerging in human economic activities, show their scope) provide the basis for achieving tangible results and developing recommendations.

The object of the research (2016) on management practices in the Sverdlovsk oblast were 110 employers - members of Sverdlovsk Regional Union of Industrialists and Entrepreneurs involved in three basic types of activity that provide employment to more than $40 \%$ human resources: manufacturing - 40 organizations (number of employees over1000 people); construction - 30 organizations (number of employees over 100 people); wholesale and retail trade- 36 organizations (number of employees over 200 people); other community, social and personal services- 4 organizations (number of employees over 200 people).

The respondents were 110 top-managers who filled in questionnaires or took part in semi-structured interviews on the questionnaire. The questionnaire aims to identify tools of competency-based HR management. 


\section{Results}

The study showed tools of competency-based HR management, using in regional HR policy, that improving the investment environment according assessment of entrepreneurs.

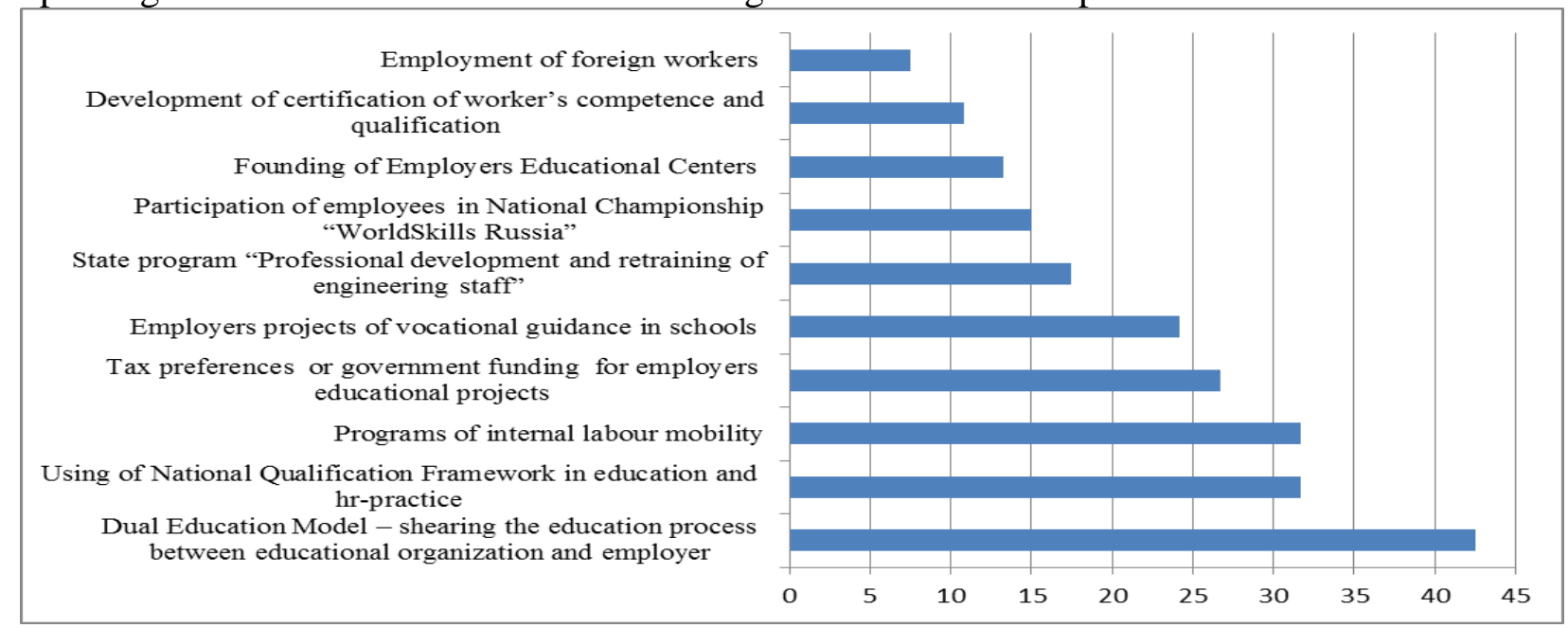

Fig. 3. Tools of the regional HR policy, using by for improving the investment environment in Sverdlovsk oblast of Russian Federation (Source: Authors' own elaboration)

\section{Conclusion}

A study of management practices in 110 organizations of the Sverdlovsk oblast showed that managers used tools of Dual Education Model, National Qualification Framework and employers labour mobility programs in education and hr-practice. According competency-based management concepts, the mechanisms of National Qualifications Frameworks: certification of professional qualifications and professional public expertise of educational programs needs to be used in Regional Human Resource Policies for Industrial Growth. Future researches can be in fields of the mechanisms of competency-based management design and developing of competency forecasting methods

\section{References}

[1]. Deist le D. F. O., Winterton J. What Is Competence? Human Resource Development International. 2005. March. Vol. 8, No 1, pp. $27-46$.

[2]. Kokovikhin A., Sharapova N., Borisov I. National system of certification of worker's competence and qualification as the institute of labour market. The 10th International Days of Statistics and Economics. Conference Proceeding, Prague, VSE. 2016, pp.871-881.

[3]. Kokovikhin A, Borisov I., Sharapova N., Sharapova V. HR-management tools as the elements of labour market adaptation mechanism. Second International Conference On Economic and Business Management (FEBM 2017). Conference Proceeding, Shanghai, Atlantis press, 2017, pp. 351-356.

[4]. Nizhegorodtsev R. M., Reznik S.D. Upravlenie kompetenciyami: struktura, instituty, mehanizmy [Competency-based management: structure, institutes, mechanisms]. Moskow, INFRA-M Publ., 2016, 208 p. 